\section{Case Reports in Ophthalmology}

\title{
Cutaneous Neurofibroma of the Lacrimal Caruncule: A Case Report
}

\author{
Mario Motta ${ }^{a, b} \quad$ Mauro Geller ${ }^{c-e}$ Cesar Motta $^{a}$ \\ ${ }^{a}$ Ophthalmology Department, Hospital Universitário Gaffrée e Guinle (UNIRIO), \\ Rio de Janeiro, Brazil; ${ }^{b}$ Ophthalmology Department, Hospital Federal dos Servidores do \\ Estado, Rio de Janeiro, Brazil; ' Clinical Genetics, Universidade Federal do Rio de Janeiro \\ (UFRJ), Rio de Janeiro, Brazil; ${ }^{d}$ Microbiology and Immunology, Faculdade de Medicina de

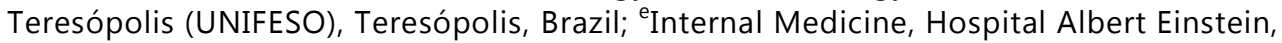 \\ São Paulo, Brazil
}

\section{Keywords}

Neurofibromatosis type 1 · Cutaneous neurofibroma - Lacrimal caruncle

\begin{abstract}
We describe the case of a neurofibroma on the lacrimal caruncle of a female patient with neurofibromatosis type 1 (NF1). NF1 is an autosomal dominant genetic disease with a wide variety of clinical manifestations, one of the most common of which is neurofibroma. The lesion was removed surgically under general anesthesia and sent to histopathological analysis, which confirmed the clinical diagnosis of a neurofibroma.

\section{Introduction}

Neurofibromatosis type 1 (NF1) is an autosomal dominant genetic disorder with widely varying clinical manifestations affecting 1:2,500 individuals worldwide [1,2]. NF1 arises as a result of mutations to the $N F 1$ gene, located on chromosome 17q11.21, a tumor suppressor gene coding for the protein neurofibromin [3]. The most common lesion is the cutaneous neurofibroma, a benign solid tumor appearing on the skin of $90 \%$ of adults with NF1. The number of cutaneous neurofibromas in an affected individual can vary from a few to several 
thousand $[3,4]$. Cutaneous neurofibroma size generally ranges from one millimeter to several centimeters [3].

\section{Case Report}

A 57-year-old female patient with confirmed clinical and genetic diagnosis of NF1 and extensive cutaneous neurofibromas throughout the body surface presented with a mass on the caruncle of the left eye. The mass was round, mobile, and could be manipulated within the eye so as to no longer be visible but occasionally spontaneously extruded from the eye (Fig. 1).

The subject underwent surgical removal of the neurofibroma under general anesthesia and the excised lesion was sent to histopathology. Histopathology analysis revealed a polypoid fragment with a small pedicule measuring $0.8 \times 0.7 \times 0.5 \mathrm{~cm}$, with firm consistency and light brownish coloration. Slicing revealed a homogenous solid nodule, whitish in color.

Microscopic analysis of histological sections revealed a nonencapsulated nodule composed of a proliferation of cells with elongated and undulated nuclei, with little individualized cytoplasm within a pale pink-colored matrix (Fig. 2, Fig. 3). No atypical features or atypical figures of mitosis were noted. The lesion was well vascularized, with dilated and congested capillary vessels, and between the conjunctiva and the epithelial surface, there was loose connective tissue that was also vascularized. The conjunctival epithelium covering the lesion exhibited squamous metaplasia and mucosecreting cells. The small pedicule contained sparse smooth muscle fibers.

\section{Discussion}

Cutaneous neurofibromas are benign lesions that can appear anywhere on the body [13]. While benign, these lesions can be present in number anywhere from a few to thousands, leading to significant cosmetic concerns for the affected patient [2]. To date, treatment of cutaneous neurofibromas relies on surgical removal, which, while effective, may lead to scarring and in cases where large numbers of neurofibromas are present may not be viable [5]. This case report highlights an unusual neurofibroma location within the left lacrimal caruncle. To our knowledge, this is the second case of a neurofibroma involving the caruncle reported in the literature [4] and the first in Brazil. Ophthalmological manifestations of NF1 include iris Lisch nodules, eyelid and orbital neurofibromas, congenital glaucoma, optic nerve gliomas, and meningiomas [5].

\section{Acknowledgements}

The authors would like to thank Sandra Moles for histopathology and Carlos Alberto Basilio for second histopathology review. 
Motta et al.: Cutaneous Neurofibroma of the Lacrimal Caruncule: A Case Report

\section{Statement of Ethics}

The patient described in this case report agreed to this publication and provided written informed consent.

\section{Disclosure Statement}

The authors have no disclosures to make.

\section{References}

1 Gutmann D, Aylsworth A, Carey J, et al: The diagnostic evaluation and multidisciplinary management of neurofibromatosis 1 and neurofibromatosis 2. JAMA 1997;278:51-57.

2 Friedman JM, Gutmann DH, MacCollin M (eds): Neurofibromatosis: Phenotype, Natural History, and Pathogenesis. 3. ed, Baltimore, Maryland, Johns Hopkins University Press, 1999 , p 381.

3 Geller M, Bonalumi Filho A (eds): Neurofibromatose: Clínica, Genética e Terapêutica. Rio de Janeiro, Guanabara Koogan, 2004, p 272.

4 Freedman KA, Tran RM: Neurofibroma involving the caruncle. Arch Opthalmol 2004;122:294-295.

5 Cunha KSG, Geller M: Advances in Neurofibromatosis Research. New York, Nova Science, 2012, p 273.

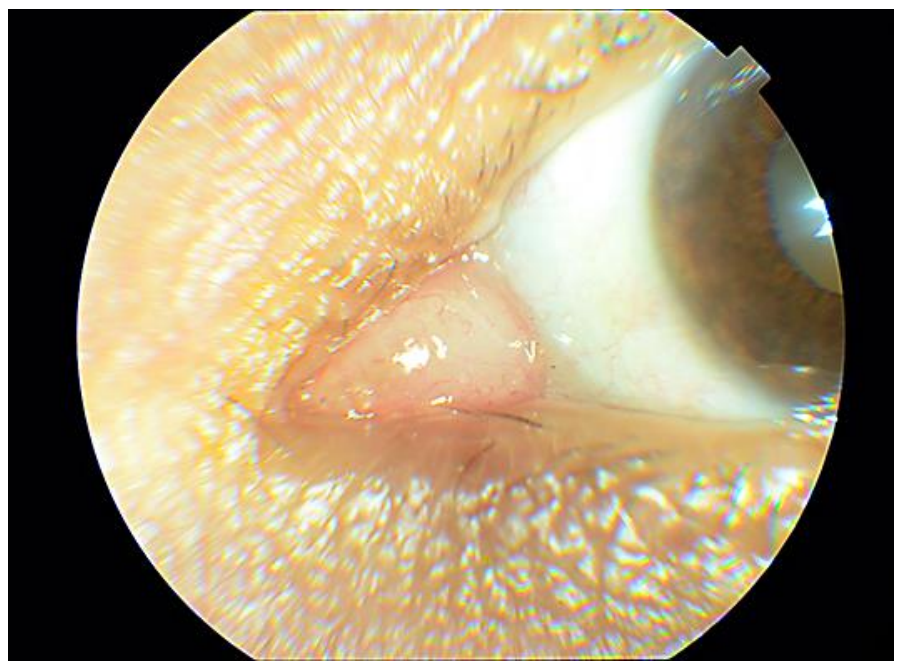

Fig. 1. Neurofibroma located on the caruncle of the left eye with visible extrusion. 


\section{Case Reports in \\ Ophthalmology}

Case Rep Ophthalmol 2017;8:358-361

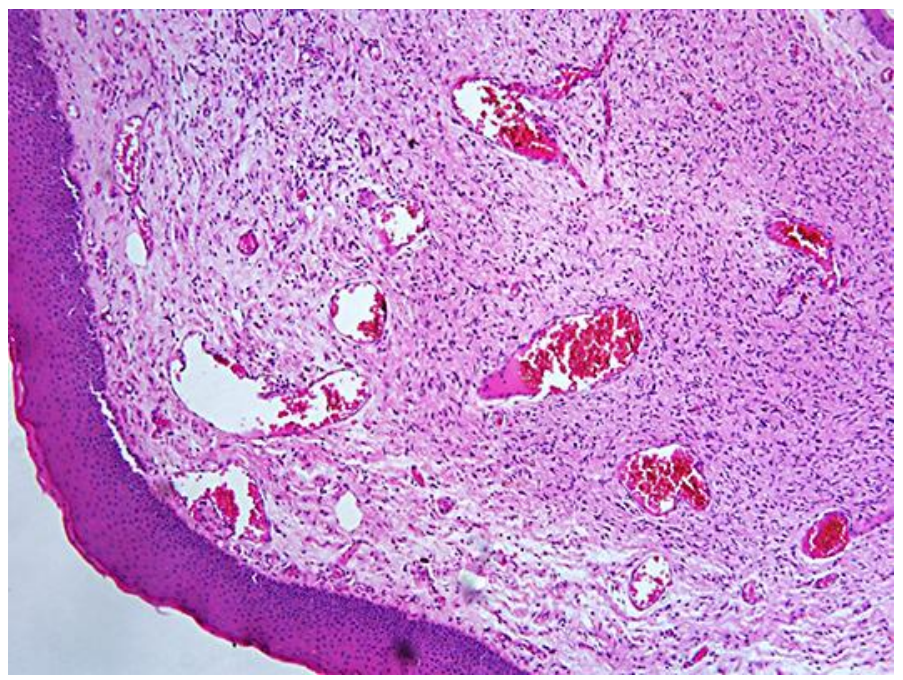

Fig. 2. Pseudoencapsulated nodular proliferation located in the corium beneath the conjunctival epithelium. Cells with ill-defined cytoplasm, arranged in bundles, presenting regular comma-shaped nuclei and stroma with collagen deposits. Squamous metaplasia on suprajacent conjunctival epithelium. Staining: H\&E.

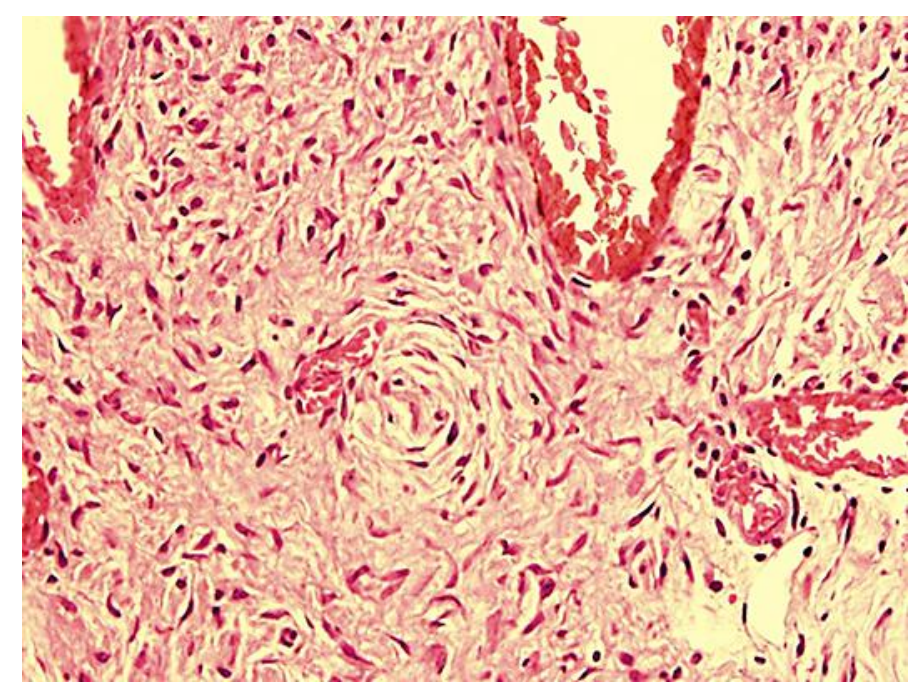

Fig. 3. Tumor detail presenting peripheral nerve sheath cells with comma-shaped nuclei. Intermingled dilated and congested capillaries. Staining: H\&E. 